\title{
Cs salt of tungstophosphoric acid-promoted zirconium titanium phosphate solid acid catalyst: An active catalyst for the synthesis of bisphenols
}

\author{
NIRANJAN BISWAL, DIPTI PRAKASINI DAS and KULAMANI PARIDA* \\ Colloids and Materials Chemistry Department, CSIR-Institute of Minerals and Materials Technology, \\ Bhubaneswar, Odisha 751 013, India \\ e-mail: paridakulamani@yahoo.com
}

MS received 27 September 2013; revised 12 November 2013; accepted 18 November 2013

\begin{abstract}
A series of novel $x$ CsTPA-ZTP ( $x=30,40,50,60$ and $80 \mathrm{wt} \%)$ solid acid composite catalysts were synthesized by ion-exchange process using cesium nitrate, tungstophosphoric acid (TPA), zirconium titanium phosphate (ZTP) with varied surface areas, acidities and microstructures. Detailed characterizations of the composite catalysts were done by Powder X-ray Diffraction (PXRD), Fourier Transform Infrared (FTIR) Spectroscopy, $\mathrm{N}_{2}$ adsorption desorption, Scanning Electron Microscopy (SEM-EDS) analysis, X-ray Photoelectron Spectroscopy (XPS) and Temperature Programmed Desorption (TPD). We have studied the catalytic activities, kinetics and reusability of the catalysts. 60CsTPA-ZTP is found to be an effective and re-usable catalyst for the synthesis of bisphenol A (BPA) and bisphenol F (BPF) using acetonitrile as solvent.
\end{abstract}

Keywords. Solid acid catalyst; CsTPA-ZTP composite; condensation reaction; bisphenol A (BPA); bisphenol F (BPF).

\section{Introduction}

Bisphenol A (BPA) and bisphenol F (BPF) are the important chemicals and/or intermediates for the preparation of industrially useful epoxy resins, phenolic resins, polycarbonates, etc. in the moulding, casting, sealing, coating, encapsulating, adhesives, laminating, reinforced plastics and other industrial chemicals. BPA and BPF are conventionally produced through acid-catalysed condensation reaction between phenol and acetone/formaldehyde (scheme 1) by using ionexchange resins promoted by mercapto compounds. BPA is industrially produced using ion-exchange resin such as Amberlyst. It was reported that ion-exchange resins or modified ion-exchange resins are used worldwide to produce BPA in industry which show good catalytic functions. However, thermal stability of resin catalysts is very limited and they cannot be used at higher reaction temperature. ${ }^{1-3}$

Again fouling of resin catalysts in the reaction medium is a problem. Some attempts have been made on the use of inorganic solid acids for BPA synthesis such as heteropolyacids, ${ }^{4}$ zeolites, ${ }^{5}$ acid functionalized mesoporous silica ${ }^{6}$ and clays. ${ }^{1}$ Hou et al. reported the

\footnotetext{
*For correspondence
}

design of inorganic mixed oxide catalyst for bisphenol A synthesis. ${ }^{7}$ They made a successful demonstration of the mixed oxide of phosphoric, boric and sulphuric acids (P:B:S ratio is $1: 2: 3$ ) calcined at $100{ }^{\circ} \mathrm{C}$ in vacuum which showed $81.6 \%$ of bisphenol $\mathrm{A}$ yield. However, this catalyst had a drawback of deactivation due to loss of sulphuric acid. ${ }^{5,8}$ It is well-known that Keggin-type tungstophosphates, $\mathrm{Cs}_{\mathrm{x}} \mathrm{H}_{3-\mathrm{x}} \mathrm{PW}_{12} \mathrm{O}_{40}$, possess super acidity and are effective in many catalysed reactions such as alkylation of aromatics, ${ }^{9,10}$ skeletal isomerisation of n-butane, ${ }^{11}$ hydrolysis of esters in excess water, ${ }^{12}$ hydration of olefins in a solidwater reaction systems, ${ }^{13}$ esterification of palmitic acid and transesterification of tributyrin. ${ }^{14}$ It is acknowledged that the substitution of $\mathrm{H}^{+}$with $\mathrm{Cs}^{+}$in Keggintype $\mathrm{H}_{3} \mathrm{PW}_{12} \mathrm{O}_{40}$ can significantly influence its acidity and microstructure. ${ }^{15}$ Recently, Ide et al. reported an effective and selective bisphenol A synthesis on a layered silicate with spatially arranged sulphonic acid. ${ }^{16}$

Previously, we have prepared CdS-pillared zirconium-titanium phosphate (ZTP), ${ }^{17} \mathrm{CdS}-\mathrm{ZnS} /$ zirconium-titanium phosphate (ZTP) ${ }^{18}$ and silver-exchanged zirconium titanium phosphate (Ag-ZTP) ${ }^{19}$ composites for different catalytic applications. Recently, we have developed $\mathrm{CdSe}$ QD/ZTP composite material ${ }^{20}$ for hydrogen production under visible light irradiation 

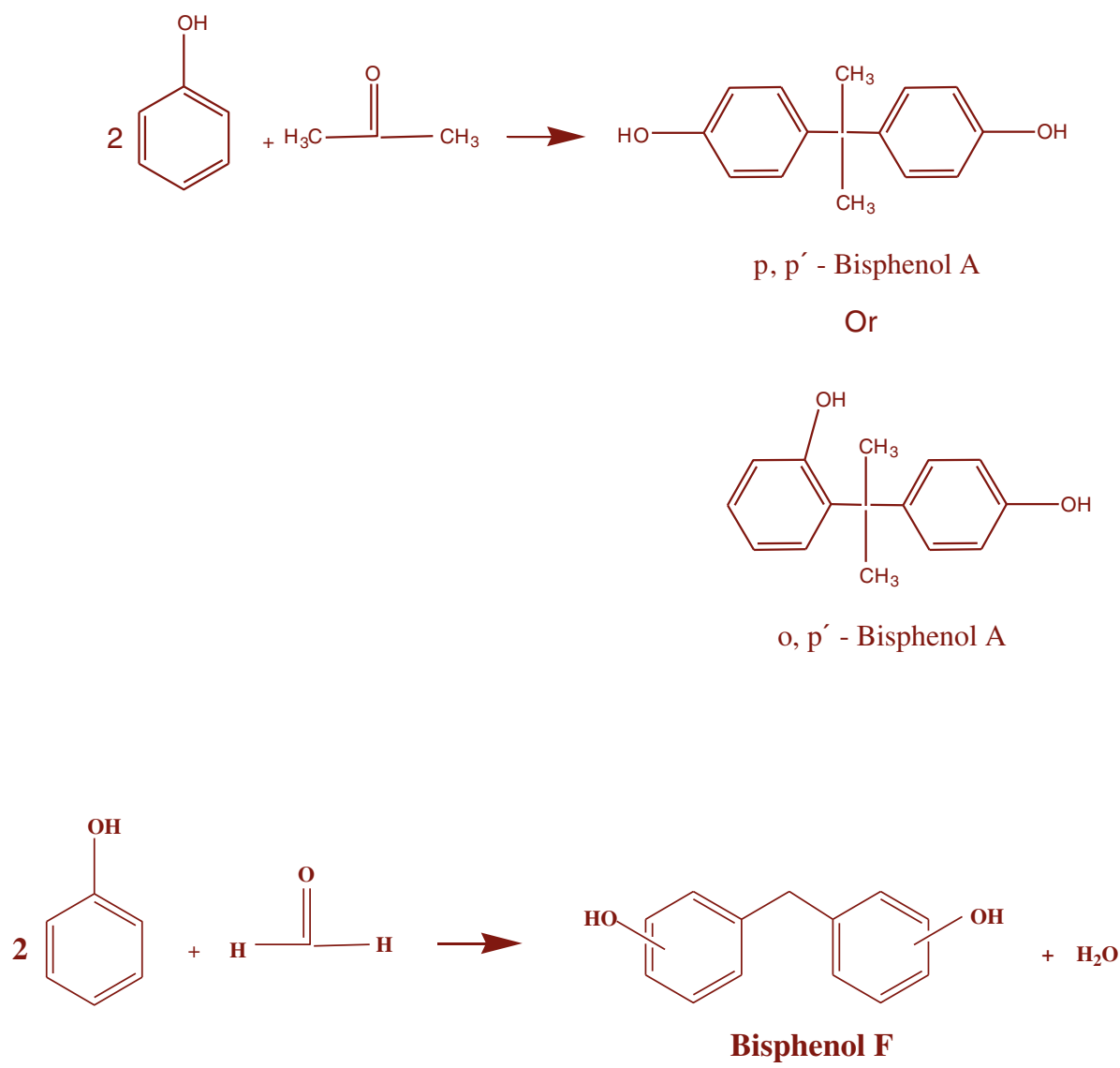

Scheme 1. Schematic representation of the formation of bisphenol A and bisphenol F.

without using any co-catalyst. In the present investigation, we have successfully synthesized $x$ CsTPAZTP $(x=30-80 \mathrm{wt} \%)$ composites by ion-exchange process with varied surface areas, acidities and microstructures. Catalytic performance of these samples for the synthesis of BPA and BPF by coupling of phenol with acetone/formaldehyde has been studied.

\section{Experiment details}

\subsection{Materials}

Cetyltrimethyl ammonium chloride $\left(\mathrm{C}_{16} \mathrm{TMACl}\right.$, Aldrich), Zirconium n-propoxide (Aldrich), Phosphoric acid (Merck), Titanium isopropoxide (Aldrich), 2-propanol (S.d. fine-Chem. Ltd.), Hydrochloric acid (Finar Chemicals Ltd.), Ethanol (Jiangsu Huaxi International Trade Co Ltd.), Cesium nitrate (Fluka), Tungstophosphoric acid (TPA, Himedia), Acetone (S.d. Fine-Chem. Ltd.), Formaldehyde (Qualigen), Acetonitrile (Merck), Phenol (S.d. Fine-Chem. Ltd.). All chemicals were of analytical grade (AR) and used as received without further purification.

\subsection{Preparation of zirconium-titanium phosphate}

ZTP with Zr:Ti molar ratio 1:3 was prepared as reported by Parida et $a l .{ }^{17}$ In a typical synthesis, cetyltrimethyl ammonium chloride was first dissolved in deionised water $(90 \mathrm{~g}, 5 \mathrm{~mol})$ by heating at $50-60{ }^{\circ} \mathrm{C}$. Zirconium n-propoxide as zirconium precursor was then added followed by a dropwise addition of $\mathrm{H}_{3} \mathrm{PO}_{4}$. The gel immediately formed was homogenized by vigorous stirring for $30 \mathrm{~min}$. Titanium isopropoxide dissolved in 2propanol was added very slowly maintaining $\mathrm{Zr}$ :Ti ratio 1:3. The $\mathrm{pH}$ of the gel was adjusted to 6.5 after $1 \mathrm{~h}$ of stirring. Finally, the gel was stirred at room temperature for 3 days. The product was filtered, washed with distilled water and dried under vacuum at room temperature. Surfactant was removed by extracting with $\mathrm{HCl} /$ ethanol solution $\left(2 \mathrm{M} \mathrm{HCl}\right.$ in ethanol) at $80{ }^{\circ} \mathrm{C}$ for $12 \mathrm{~h}$. This is designated as ZTP.

\subsection{Preparation of Cs salt of tungstophosphoric acid-ZTP (xCsTPA-ZTP) composite}

$x$ CsTPA-ZTP composites were prepared by varying the wt\% of Cs salt of tungstophosphoric acid from 30$80(x=30,40,50,60$ and $80 \mathrm{wt} \%)$ by ion-exchange 
process. In a typical experiment, different $\mathrm{wt} \%$ of $\mathrm{Cs}^{+}$ was exchanged using $\mathrm{CsNO}_{3}$ as precursor onto the support ZTP by stirring for $24 \mathrm{~h}$. After subsequent washing and drying, CsTPA-ZTP was prepared by stirring stoichiometric amount of tungstophosphoric acid in a suspension of Cs-ZTP $\left(\mathrm{Cs}^{+}\right.$-exchanged ZTP) for $12 \mathrm{~h}$. These samples were dried and designated as $x$ CsTPAZTP (where $x=30,40,50,60$ and $80 \mathrm{wt} \%$ ).

\subsection{Characterizations}

The samples were characterized by BAXS, FTIR, $\mathrm{N}_{2}$ adsorption desorption studies, SEM-EDS, XPS and TPD studies. Broad angle X-ray diffraction (BAXS) patterns were recorded on a Rigaku Miniflex (set at $30 \mathrm{kV}$ and $15 \mathrm{~mA}$ ) powder diffractometer using $\mathrm{Cu} \mathrm{K} \alpha$ radiation within the $2 \theta$ range from 10 to $70^{\circ}$ at a rate of $5 \%$ min in step of $0.01^{\circ} . \mathrm{N}_{2}$ adsorption-desorption studies were carried out by ASAP 2020 (Micromeritics) instrument at liquid nitrogen temperature $\left(-196{ }^{\circ} \mathrm{C}\right)$. Prior to analysis, the particles were subjected to vacuum $\left(10^{-5}\right.$ torr) at $110{ }^{\circ} \mathrm{C}$ for $5 \mathrm{~h}$ to ensure a clean surface. Surface area was calculated with BrunauerEmmett-Teller (BET) method using the adsorption data within the $\left(P / P_{\circ}\right)$ range from 0.05 to 0.33 . The pore volumes were taken at a relative pressure $\left(P / P_{\circ}\right)$ of 0.95 . Pore size distribution was obtained using BarrettJoyner-Halenda (BJH) model using desorption branch of isotherm. Scanning electron microscopic (SEM) images and semiquantitative EDS microanalyses were taken by Hitachi S-3400N. Prior to the analyses, the samples were sputtered with a thin film of gold. Fourier Transform Infrared (FTIR) spectra were recorded on Varian FTIR spectrophotometer (FTS 800) in the range $4000-400 \mathrm{~cm}^{-1}$ using $\mathrm{KBr}$ wafers. Each spectrum was recorded at $4 \mathrm{~cm}^{-1}$ resolution with 30 scans. X-ray photoelectron spectroscopy (XPS) measurements were performed by VG Microtech Multilab ESCA 3000 spectrometer with a non-monochromatic $\mathrm{Mg}-\mathrm{K} \alpha$ X-ray source. Energy resolution of the spectrometer was set at $0.8 \mathrm{eV}$ with $\mathrm{Mg}-\mathrm{K} \alpha$ radiation at pass energy of $50 \mathrm{eV}$. The binding energy correction was performed using the $\mathrm{C} 1 \mathrm{~s}$ peak of carbon at $284.9 \mathrm{eV}$ as reference. Temperature programmed desorption (TPD) profiles were obtained by AutoChem 2920 (Micromeritics). About $0.05 \mathrm{~g}$ of the sample was housed in a quartz U-tube. Prior to analysis, the samples were degassed at $110{ }^{\circ} \mathrm{C}$ for $2 \mathrm{~h}$ under $\mathrm{N}_{2}$ flow $(50 \mathrm{~mL} / \mathrm{min})$. It was cooled down to $40{ }^{\circ} \mathrm{C}$. The samples were saturated with $\mathrm{NH}_{3}$ by the flow of $20 \% \mathrm{NH}_{3}$ /balanced $\mathrm{He}$ for $30-40 \mathrm{~min}(25 \mathrm{~mL} / \mathrm{min})$. The $\mathrm{N}_{2}$ gas was flowed over catalyst $(50 \mathrm{~mL} / \mathrm{min})$ for $30 \mathrm{~min}$ to remove the physisorbed $\mathrm{NH}_{3}$. The temperature was increased from $40^{\circ}$ to $900{ }^{\circ} \mathrm{C}$ with the flow of $\mathrm{N}_{2}(50 \mathrm{~mL} / \mathrm{min})$ to get the TPD profile. The amount of $\mathrm{NH}_{3}$ consumed was determined by TCD detector which gives the amount of Bronsted and Lewis acid sites in the sample. Before the experiment, the above said equipment was calibrated by $20 \% \mathrm{NH}_{3}$ /balanced He to know the exact amount of gas consumed during the experiment.

\subsection{Catalytic activity}

Catalytic activity of the catalysts was studied at different parametric conditions such as wt $\%$ loading of CsTPA onto ZTP, temperature, time, molar ratio of phenol to acetone, etc. Synthesis of bisphenol A/bisphenol $\mathrm{F}$ was carried out in a two-necked round bottom flask charged with $50 \mathrm{mg}$ of the composite catalyst, $8 \mathrm{mmol}$ of phenol and $1 \mathrm{mmol}$ of acetone/formaldehyde using acetonitrile as solvent which was stirred at $70{ }^{\circ} \mathrm{C}$ for $7 \mathrm{~h}$. From the said condition, we obtained the maximum conversion and selectivity of BPA and BPF, respectively. After the reaction, the product was separated from the catalyst by filtration and analysed by Shimadzu GC-2010 with a capillary column; ZB-5. Conversion (\%) of phenol and selectivity (\%) of BPA and $\mathrm{BPF}$ are calculated with the following formulae.

$$
\begin{aligned}
& \text { Conversion }(\%)_{\text {reactant }}=\left(\frac{\text { Reactant converted (moles) }}{\text { Reactant used (moles) }}\right) \times 100 \\
& \text { Selectivity }(\%)_{\text {product }}=\left(\frac{\text { Product formed (moles) }}{\text { Reactant converted (moles) }}\right) \times 100
\end{aligned}
$$

\section{Results and discussion}

\subsection{Characterization of catalysts}

The PXRD pattern of $x$ CsTPA-ZTP (figure 1a) showed that the composites are crystalline in nature. There is not much change in the crystallinility with increase in the wt\% of CsTPA salt onto the support which is in agreement with Zhang et al. ${ }^{21}$ Diffraction patterns matched with the patterns of CsTPA reported by Satsuma et al. ${ }^{22}$ which confirmed that the composite of CsTPA-ZTP was formed. The indexed peaks are for CsTPA, some of the peaks of ZTP overlap with these CsTPA peaks and the un-indexed peaks are for neat ZTP. The peak with $d$ value of $3.9 \AA$ (JCPDS-34-1237) in figure $1 \mathrm{~b}$ shows the formation of ZTP.

Textural characterization of $x$ CsTPA-ZTP composite was determined by $\mathrm{N}_{2}$ BET surface area and pore analysis (table 1). The nitrogen adsorption-desorption 

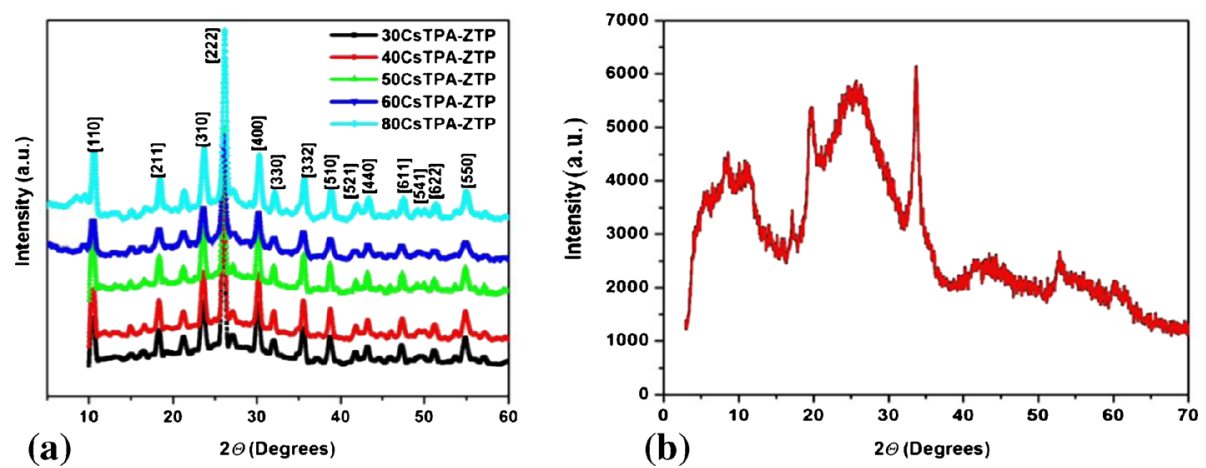

Figure 1. PXRD patterns of (a) $x$ CsTPA-ZTP composite, and (b) neat ZTP.

isotherms of all samples are shown in figure 2(a). For all the samples, it shows type IV isotherm and H1 hysteresis loop as defined by IUPAC which confirms the mesoporosity of all the composite samples. ${ }^{17,18}$ In the isotherms, two clear distinct phases can be recognized (i) a slow enhance in nitrogen uptake at low relative pressures, resulting in monolayer-multilayer adsorption on pore walls and (ii) relatively sharp step at higher relative pressures associated with multilayer adsorption. Also, the pore size and pore volume distribution of the catalysts are shown in figure 2(b). The BJH average pore size and pore volume of neat ZTP are $4.0 \mathrm{~nm}$ and $0.55 \mathrm{~cm}^{3} / \mathrm{g}$, respectively. Also, the $\mathrm{BJH}$ average pore size and pore volume are found to be in the range of 7.9 to $9.4 \mathrm{~nm}$ and 0.25 to $0.33 \mathrm{~cm}^{3} / \mathrm{g}$ for all the $x$ CsTPAZTP composite samples. The composite materials do not follow the specific trend. It is found that the pore size and pore volume are nearly same from 30CsTPAZTP to 60CsTPA-ZTP, i.e., 8.0 to $8.1 \mathrm{~nm}$ and 0.28 to $0.25 \mathrm{~cm}^{3} / \mathrm{g}$, respectively. ${ }^{23}$ In the case of 80CsTPA-ZTP, the pore size and pore volume are slightly greater than the other composites, i.e., $9.4 \mathrm{~nm}$ and $0.33 \mathrm{~cm}^{3} / \mathrm{g}$. Pore sizes of all the catalysts lie in the mesostructured region. It can be observed that the pore-size distribution curve becomes somewhat broader; however, pore-size distribution still remains very narrow with major fractions of pores lying within the 7.9 A region. From table 1, it was found that the neat ZTP and $x$ CsTPA-ZTP (where $x=$ $30,40,50,60$ and $80 \mathrm{wt} \%$ ) composite have surface area $102 \mathrm{~m}^{2} / \mathrm{g}$ and $54-72.3 \mathrm{~m}^{2} / \mathrm{g}$, respectively. It is examined that the surface areas are nearly same from 30CsTPAZTP to 60CsTPA-ZTP, i.e., 54.0 to $53.4 \mathrm{~m}^{2} / \mathrm{g}$. ${ }^{23}$ Surface area of 80CsTPA-ZTP is $72.3 \mathrm{~m}^{2} / \mathrm{g}$ which might be due to the presence of some extra CsTPA salt on the surface of the catalyst. Surface area of composite materials in comparison to the neat ZTP is reduced which suggests that the catalysts just physically block the pore structure of the ZTP. ${ }^{18,20}$

Figure 3(a) depicts the FTIR spectra of the neat ZTP and $x$ CsTPA-ZTP composites. Broad bands in the hydroxyl region $\left(3600-3200 \mathrm{~cm}^{-1}\right.$ ) with largely at $3400 \mathrm{~cm}^{-1}$ were consigned to the $\mathrm{O}-\mathrm{H}$ stretching vibration of the remaining water, transferable $\mathrm{OH}^{-}$, and imperfect $\mathrm{OH}$ groups with significant hydrogen bonding. Owing to the $\mathrm{C}-\mathrm{H}$ stretching vibration, no absorption peaks at 1480 and $2800-3000 \mathrm{~cm}^{-1}$ were detected which indicated that the surfactant was fully taken away by $\mathrm{HCl} / \mathrm{EtOH}$ solvent extraction. The pointed peak in the area $1600-1700 \mathrm{~cm}^{-1}$ shows the existence of $\mathrm{H}_{3} \mathrm{O}^{+}$(Bronsted acidity). ${ }^{24}$ The typical band at $1072.63 \mathrm{~cm}^{-1}(\mathrm{P}-\mathrm{O}$ in the central tetrahedral $)$ is present in Keggin ion. The existence of $\delta(\mathrm{POH})$ is

Table 1. Surface properties of $x$ CsTPA-ZTP composite.

\begin{tabular}{lcccc}
\hline Catalyst & $\begin{array}{c}\text { Surface area } \\
\left(\mathrm{BET}, \mathrm{m}^{2} / \mathrm{g}\right)\end{array}$ & $\begin{array}{c}\text { Average pore } \\
\text { size }(\mathrm{nm})\end{array}$ & $\begin{array}{c}\text { Pore volume } \\
\left(\mathrm{cm}^{3} / \mathrm{g}\right)\end{array}$ & CsTPA $(\mathrm{wt} \%)^{\mathrm{a}}$ \\
\hline ZTP & 102 & 4.0 & 0.55 & 0 \\
30CsTPA-ZTP & 54 & 8.0 & 0.28 & 20.52 \\
40CsTPA-ZTP & 50 & 7.9 & 0.29 & 26.32 \\
50CsTPA-ZTP & 51 & 7.9 & 0.26 & 31.54 \\
60CsTPA-ZTP & 53.4 & 8.1 & 0.25 & 33.95 \\
80CsTPA-ZTP & 72.3 & 9.4 & 0.33 & 33.02 \\
\hline
\end{tabular}

${ }^{\text {a}}$ Determined by EDX studies 

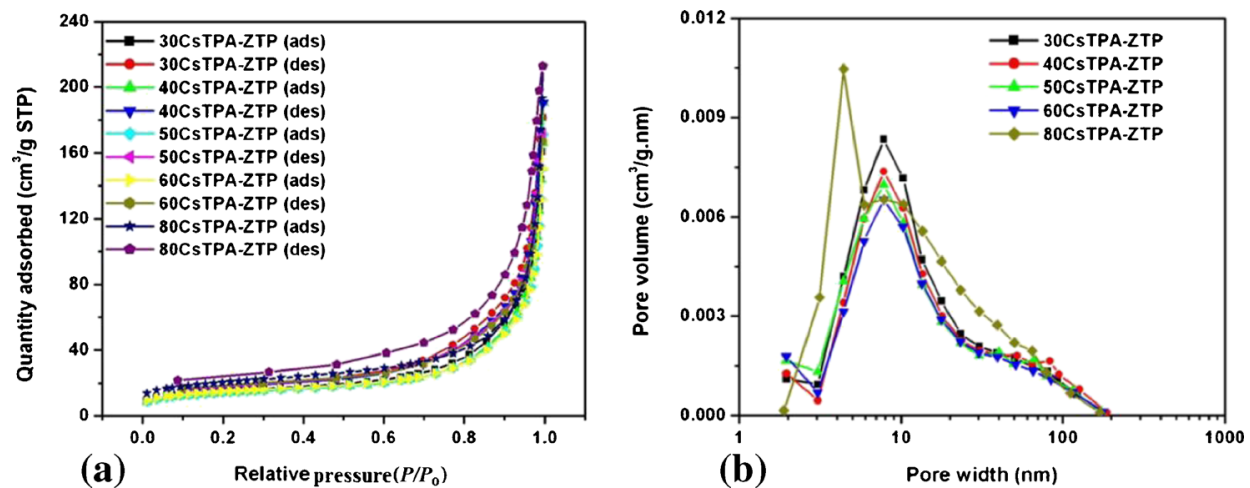

Figure 2. (a) $\mathrm{N}_{2}$ adsorption-desorption studies. (b) BJH-pore size distribution of $x$ CsTPA-ZTP.

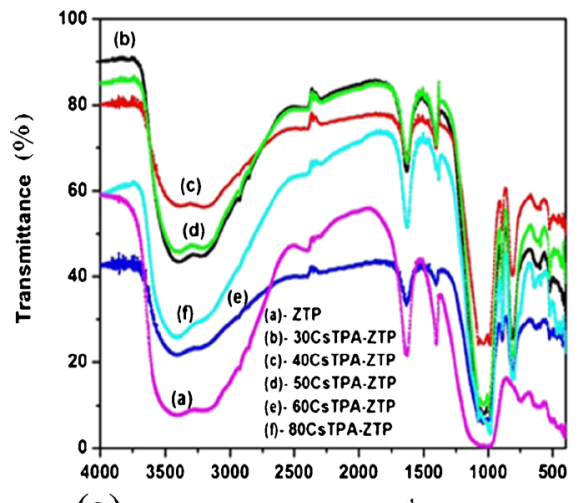

(a)

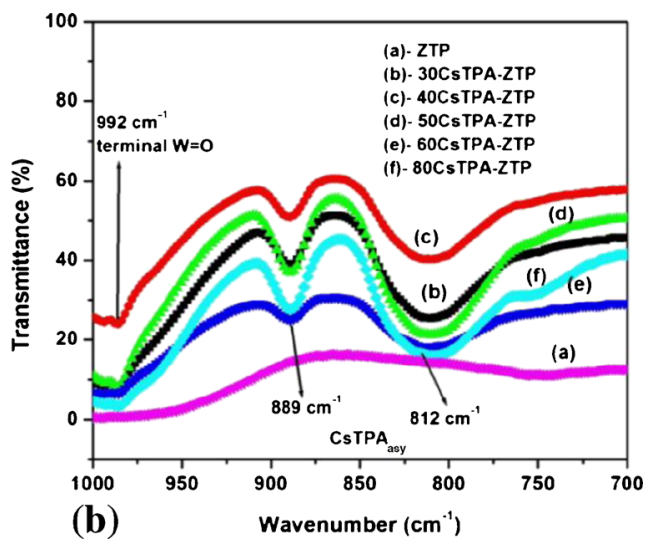

Figure 3. (a) FTIR spectra of $x$ CsTPA-ZTP $(x=0-80 \mathrm{wt} \%)$ composite. (b) FTIR spectra of the composites designating the important band positions.

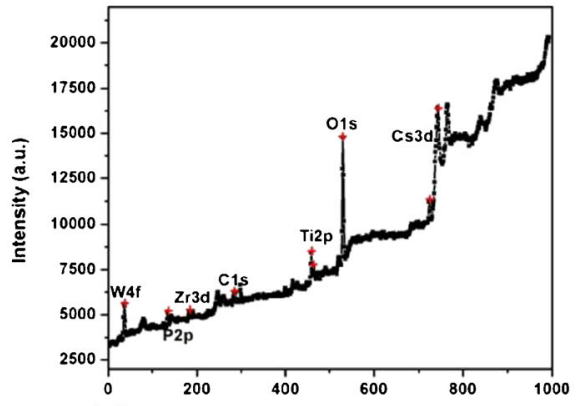

(a)

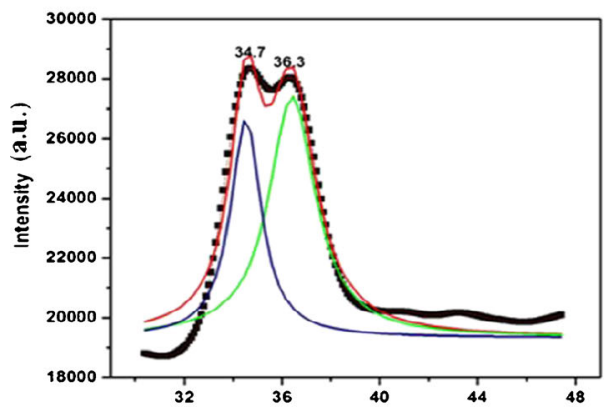

(c)

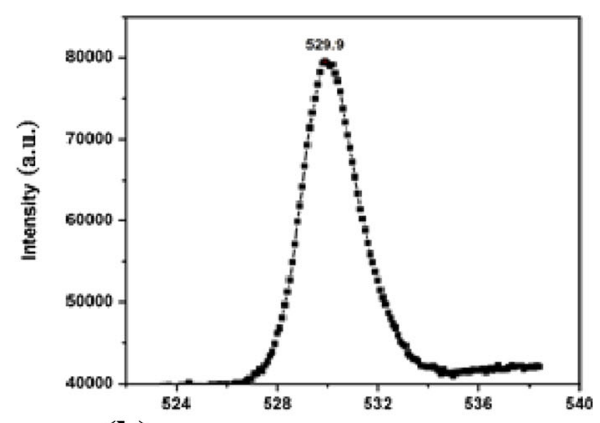

(b)

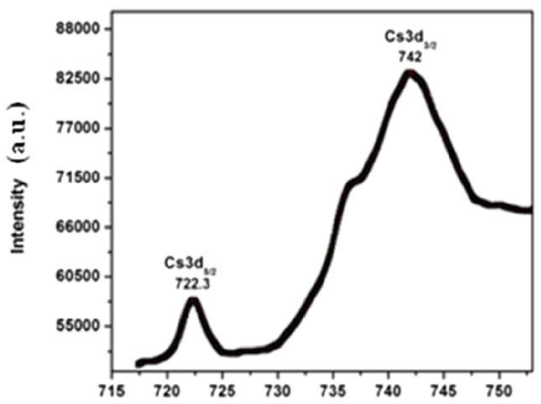

(d) Binding energy (en)

Figure 4. (a) Total survey, (b) O1s, (c) W4f, and (d) Cs3d spectra of CsTPA-ZTP. 


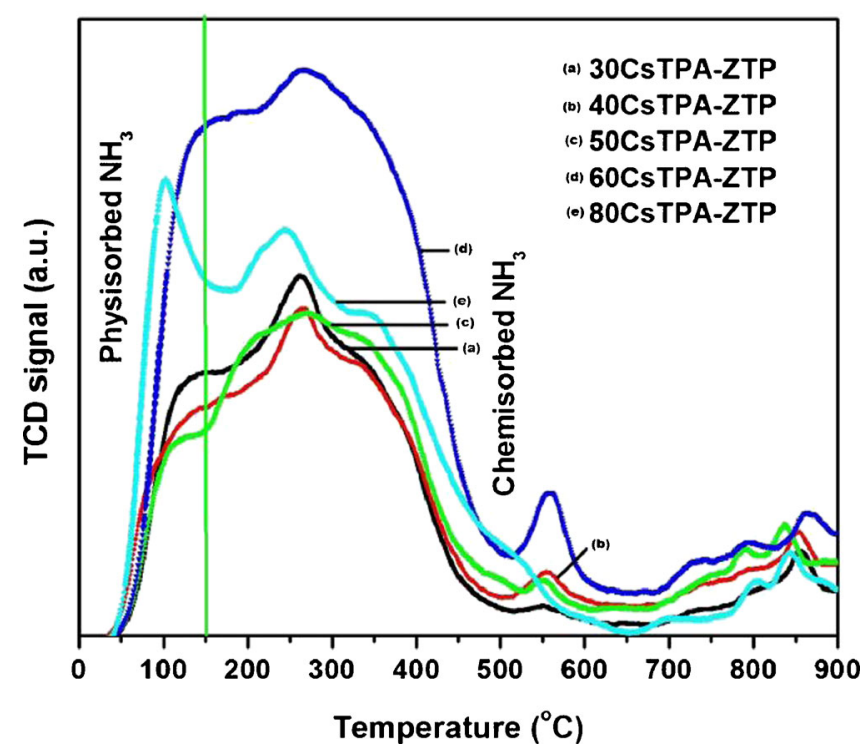

Figure 5. $\mathrm{NH}_{3}$ TPD profile of CsTPA-ZTP composites.

known from the standard intensity peak at $1400 \mathrm{~cm}^{-1}$. These bands specify the presence of structural hydroxyl groups/protonic sites in the material. In these composites, the small band (ca. $953 \mathrm{~cm}^{-1}$ ) become visible in the $\mathrm{P}-\mathrm{O}$ stretching region was assigned to TiO-P or Zr-O-P vibrations. ${ }^{19}$ From the observation of figure 3(a), it is clear that all the composites show no structural loss. It is visible that the bands at 992 (terminal $\mathrm{W}=\mathrm{O}$ ) $\mathrm{cm}^{-1}, 889$ and $812 \mathrm{~cm}^{-1}$ (W-OW) asymmetric vibrations are associated with Keggin ion (figure $3 b$ ). The Cs-DTP is specifically illustrated by a split in the $\mathrm{W}=\mathrm{O}$ band. This doublet signifying that a direct contact among the polyanion and $\mathrm{Cs}^{+}$ exists. ${ }^{25-29}$

Figure 4(a) depicts the total XPS survey of CsTPAZTP and few major individual elements. Binding energy of $\mathrm{O} 1 \mathrm{~s}$ is decreased to $529.9 \mathrm{eV}$ (figure 4b) which shows that $\mathrm{Cs}$ is getting exchanged. ${ }^{30}$ The bands of $\mathrm{W} 4 \mathrm{f}$ electron are visible at 34.7 and $36.3 \mathrm{eV}$. The band at $36.3 \mathrm{eV}$ may be interpreted due to presence of
$\mathrm{W}^{6+}$ and the band at $34.7 \mathrm{eV}$ is mainly due to presence of reduced species of tungsten which might be due to the high vacuum ESCA studies (figure 4c). ${ }^{31}$ The bands of $\mathrm{Cs} 3 \mathrm{~d}$ electron are noticeable at 722.3 and $742 \mathrm{eV}$ (figure 4d). Apart from that, a less intense band is observed at $78.03 \mathrm{eV}$ for $\mathrm{Cs} 4 \mathrm{~d}$ electrons (figure $4 \mathrm{a}$ ). ${ }^{32}$

Figure 5 shows the $\mathrm{NH}_{3}$ TPD profile of CsTPAZTP with varied concentration of CsTPA onto ZTP composite. The $\mathrm{NH}_{3}$ TPD profile shows peaks which are observed in low temperature range $\left(\mathrm{LT}<500{ }^{\circ} \mathrm{C}\right.$ ) and high temperature range $\left(\mathrm{HT}>500{ }^{\circ} \mathrm{C}\right)$. It possesses mainly two peaks which indicate the presence of two types of acid sites, i.e., Bronsted and Lewis acid sites in the composite materials. The mainly two peaks are around at $250{ }^{\circ} \mathrm{C}$ and $550{ }^{\circ} \mathrm{C}$. At higher temperature $\left(>760{ }^{\circ} \mathrm{C}\right)$, some peaks are detected. As cesiumsubstituted dodecatungstophosphoric acid-based materials mainly contains Bronsted acid sites, the present material may acquire a large amount of these acid sites. ${ }^{24}$ From table 2, it is found that the concentration of acid sites increases ( 0.56 to $1.29 \mu \mathrm{mol} / \mathrm{g})$ with the increase of the CsTPA up to $60 \mathrm{wt} \%$ and thereafter it decreases slightly $(0.91 \mu \mathrm{mol} / \mathrm{g})$. This might be due to the reduction of exchange of $\mathrm{Cs}^{+}$during ion exchange process at $80 \mathrm{wt} \%$ concentration which is also evidenced from the EDX data presented in table 1. Concentration of acidic sites for composite materials in high temperature region $\left(>500{ }^{\circ} \mathrm{C}\right)$ is very low $(0.06$ to $0.12 \mu \mathrm{mol} / \mathrm{g})$ comparison to the concentration of acidic sites in low temperature region $\left(<500{ }^{\circ} \mathrm{C}\right)$. Details of acid strengths are summarized in table 2 .

\subsection{Performance of the catalysts}

Tables 3 and 4 depict the activities of various solid acid catalysts toward the coupling reactions for the formation of (BPA) and (BPF) with rate of formation of

Table 2. $\mathrm{NH}_{3}$ TPD ${ }^{\mathrm{a}}$ results of $x$ CsTPA-ZTP.

\begin{tabular}{|c|c|c|c|}
\hline \multirow[b]{2}{*}{ Catalyst } & \multirow[b]{2}{*}{$\begin{array}{l}\text { Acid sites/unit surface } \\
\text { area }\left(\mu \mathrm{mols}^{-1}\right)\end{array}$} & \multicolumn{2}{|c|}{ TPD of $\mathrm{NH}_{3}(\mu \mathrm{mol} / \mathrm{g})$} \\
\hline & & $\begin{array}{l}\text { LT-Peak } \\
\left(<500^{\circ} \mathrm{C}\right)\end{array}$ & $\begin{array}{l}\text { HT-Peak } \\
\left(>500^{\circ} \mathrm{C}\right)\end{array}$ \\
\hline 30CsTPA-ZTP & 27.4 & 0.56 & 0.11 \\
\hline 40CsTPA-ZTP & 105.32 & 0.79 & 0.08 \\
\hline 50CsTPA-ZTP & 43.0 & 0.83 & 0.11 \\
\hline 60CsTPA-ZTP & 89.79 & 1.29 & 0.06 \\
\hline 80CsTP-ZTP & 16.95 & 0.91 & 0.12 \\
\hline
\end{tabular}

${ }^{\text {a }}$ Values determined after deducting the amount of physisorbed $\mathrm{NH}_{3}$ at temperature $<150{ }^{\circ} \mathrm{C}$. 
Table 3. Conversion of phenol and selectivity towards the formation of BPA and BPF.

\begin{tabular}{lcccc}
\hline Catalysts & $\begin{array}{c}\text { BPA } \\
\text { conversion }(\%)\end{array}$ & $\begin{array}{c}\text { BPF } \\
\text { conversion }(\%)\end{array}$ & $\begin{array}{c}\text { BPA selectivity } \\
(\%)\end{array}$ & $\begin{array}{c}\text { BPF selectivity } \\
(\%)\end{array}$ \\
\hline ZTP & 3 & 6.5 & 5 & 6.25 \\
CsTPA & 10 & 10 & 5 & 7.20 \\
30 CsTPA-ZTP & 25 & 28.9 & 30.3 & 33.45 \\
40 CsTPA-ZTP & 38.95 & 41.23 & 52 & 55.3 \\
50 CsTPA-ZTP & 50.23 & 58.52 & 68.92 & 73.9 \\
60 CsTPA-ZTP & 60.87 & 69.73 & 83.82 & 87.95 \\
80 CsTPA-ZTP & 61.9 & 70 & 85 & 90 \\
\hline
\end{tabular}

Table 4. Rate of formation of BPA and BPF as a function of wt $\%$ of CsTPA onto ZTP.

\begin{tabular}{lcc}
\hline Catalysts & $\begin{array}{c}\text { Rate of BPA formation } \\
(\mathrm{mmol} / \mathrm{g} / \mathrm{h})\end{array}$ & $\begin{array}{c}\text { Rate of BPF formation } \\
(\mathrm{mmol} / \mathrm{g} / \mathrm{h})\end{array}$ \\
\hline ZTP & 0.57 & 0.714 \\
CsTPA & 1.23 & 1.56 \\
30 CsTPA-ZTP & 3.46 & 3.82 \\
40 CsTPA-ZTP & 5.94 & 6.32 \\
50 CsTPA-ZTP & 7.88 & 8.45 \\
60 CsTPA-ZTP & 9.57 & 10.05 \\
80 CsTPA-ZTP & 9.71 & 10.28 \\
\hline
\end{tabular}

Reaction condition: $($ Catalyst $)=0.05 \mathrm{~g} ;$ Phenol:Acetone/formaldehyde $=8: 1$; Temperature $=70^{\circ} \mathrm{C}$.
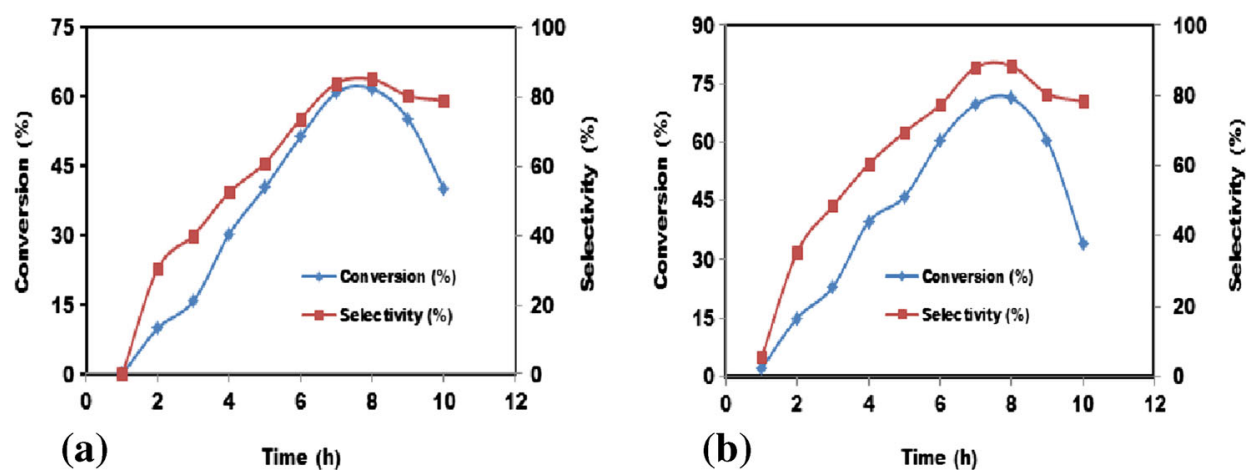

Figure 6. Conversion and selectivity of (a) BPA and (b) BPF as a function of reaction time. Reaction condition: [60CsTPA-ZTP] $=0.05 \mathrm{~g}$; Phenol:Acetone/formaldehyde $=$ $8: 1$; Temperature $=70{ }^{\circ} \mathrm{C}$.

$\mathrm{BPA}$ and BPF. As observed, the pristine $\mathrm{ZTP}^{17}$ having highest surface area, i.e., $102 \mathrm{~m}^{2} / \mathrm{g}$ shows the lowest phenol conversion, i.e., $3 \%$ and $6.5 \%$, lowest selectivity, i.e., $5 \%$ and $6.25 \%$ towards the formation of BPA and BPF, respectively. This is because of the fact that ZTP contains strong acidic sites at high temperature (HT), ${ }^{33,34}$ which are not effective for the formation of $p, p^{\prime}$-BPA. Also, CsTPA shows the conversion, i.e., $10 \%$ towards BPA and BPF with $5 \%$ selectivity for BPA and $7.2 \%$ BPF. It is clearly observed from tables 3 and 4, the selectivity as well as the rate of formation of BPA increases from $5-83.82 \%$ and $0.57-9.71 \mathrm{mmol} / \mathrm{g} / \mathrm{h}$, respectively with increase in the wt\% of CsTPA onto the pristine ZTP up to $60 \mathrm{wt} \%$. This is very much coherent with the low temperature acid concentration $(1.45 \%)$ which is maximum for 60CsTPA-ZTP. Our observation is in agreement with the report published by Rode et al. ${ }^{34}$ Similar observations were noticed on the formation of BPF with selectivity enhancement from $6.25-87.95 \%$ and 
Table 5. Temperature-dependent conversion and selectivity for coupling reactions.

\begin{tabular}{lccccc}
\hline & \multicolumn{2}{c}{ Phenol conversion (\%) } & & \multicolumn{2}{c}{ Selectivity (\%) } \\
\cline { 2 - 3 } \cline { 5 - 6 } Temperature $\left({ }^{\circ} \mathrm{C}\right)$ & $\begin{array}{c}\text { Phenol-acetone } \\
\text { coupling }\end{array}$ & $\begin{array}{c}\text { Phenol- } \\
\text { formaldehyde coupling }\end{array}$ & BPA & BPF \\
\hline 60 & 55.62 & 62.59 & & 78.23 & 81.36 \\
70 & 61.73 & 71.20 & & 85.00 & 88.35 \\
80 & 65.39 & 72.93 & & 79.49 & 81.43 \\
90 & 70.43 & 78.45 & & 70.2 & 77.95 \\
\hline
\end{tabular}

Reaction conditions: $(60 \mathrm{CsTPA}-\mathrm{ZTP})=0.05 \mathrm{~g}$; Phenol:Acetone/formaldehyde $=8: 1 ;$ Reaction time $=7 \mathrm{~h}$

rate of BPF formation from $0.714-10.28 \mathrm{mmol} / \mathrm{g} / \mathrm{h}$. With further increase in the wt $\%$ of CsTPA onto ZTP, the selectivity and rate of formation remain almost same. In case of BPA, biproducts such as chromans and triphenols were not identified, rather a minor quantity of o, $\mathrm{p}^{\prime}$-BPA was observed at higher wt $\%$ of CsTPA (>50 wt $\%$ ) supported ZTP. In case of BPF formation, carbinol was identified as the side product since the trimer formation is favoured at HT acidic concentration. $^{34}$

The activity of 60 CsTPA-ZTP was studied towards the formation of BPA and BPF as a function of reaction time (figure 6). The experiments were carried out in the time range of 1-10 h. One can see, the conversion of phenol and selectivity towards the formation of $\mathrm{p}, \mathrm{p}^{\prime}-\mathrm{BPA}$ and BPF are rapidly increasing. At $7 \mathrm{~h}$, the phenol conversion reached maximum, i.e., $61.73 \%$ and selectivity towards p,p'-BPA at $85 \%$ (figure $6 a$ ). Thereafter, with increase in the reaction time, the conversion and selectivity drop to $40.2 \%$ and $78.9 \%$ at $10 \mathrm{~h}$ (figure 6a). Similarly, at $7 \mathrm{~h}$, maximum phenol conversion, i.e., $71.2 \%$ and selectivity, i.e., $88.35 \%$ towards p, $\mathrm{p}^{\prime}$-BPF formation drop to $33.92 \%$ and $78.3 \%$, respec tively, at $10 \mathrm{~h}$ (figure 6b). This is mainly due to the deactivation of catalyst with the formation of water during the reactions (scheme 1). ${ }^{7}$

Also, to know the effect of reaction temperature on the conversion of phenol and selectivity towards BPA and BPF, we have carried out the experiments with fixed catalyst concentration, molar ratio of phenol to ketone/aldehyde in a range of reaction temperatures from $60-90{ }^{\circ} \mathrm{C}$. As mentioned in table 5, conversion of phenol in both the coupling reactions is increases with increase in temperature, but the selectivity of BPA and BPF decreases which is in good agreement with the report by Das et al. ${ }^{6}$

Recyclability test was performed thrice by activating the used 60 CsTPA-ZTP catalyst. After the first experiment, the catalyst was washed several times with acetonitrile and dried at $110{ }^{\circ} \mathrm{C}$ overnight. The same procedure was followed during the second and third time. It was observed that the said catalyst showed nearly same conversion and selectivity compared to fresh one. Again, the used catalysts were tested using FTIR technique. It is well-observed from figure 7(a) that there is not much difference in the spectra of the fresh and

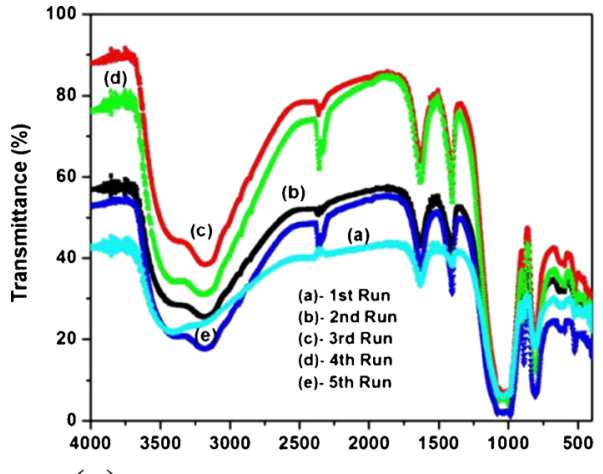

(a) Wavenumber $\left(\mathrm{cm}^{-1}\right)$

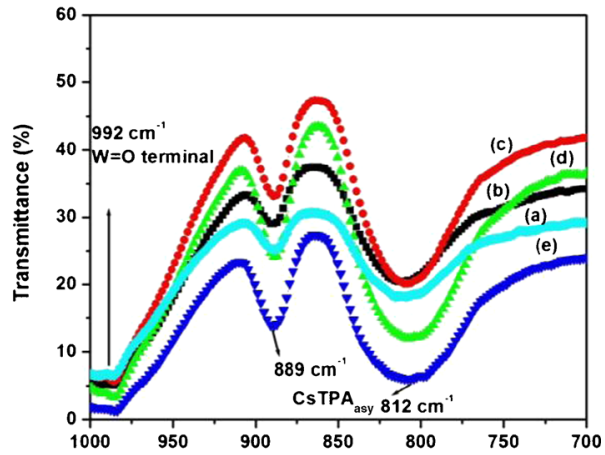

(b)

Wavenumber $\left(\mathrm{cm}^{-1}\right)$

Figure 7. (a) FTIR spectra of used 60CsTPA-ZTP catalyst for BPA and BPF synthesis process. (b) Designation of important band positions from $1000-700 \mathrm{~cm}^{-1}$. 


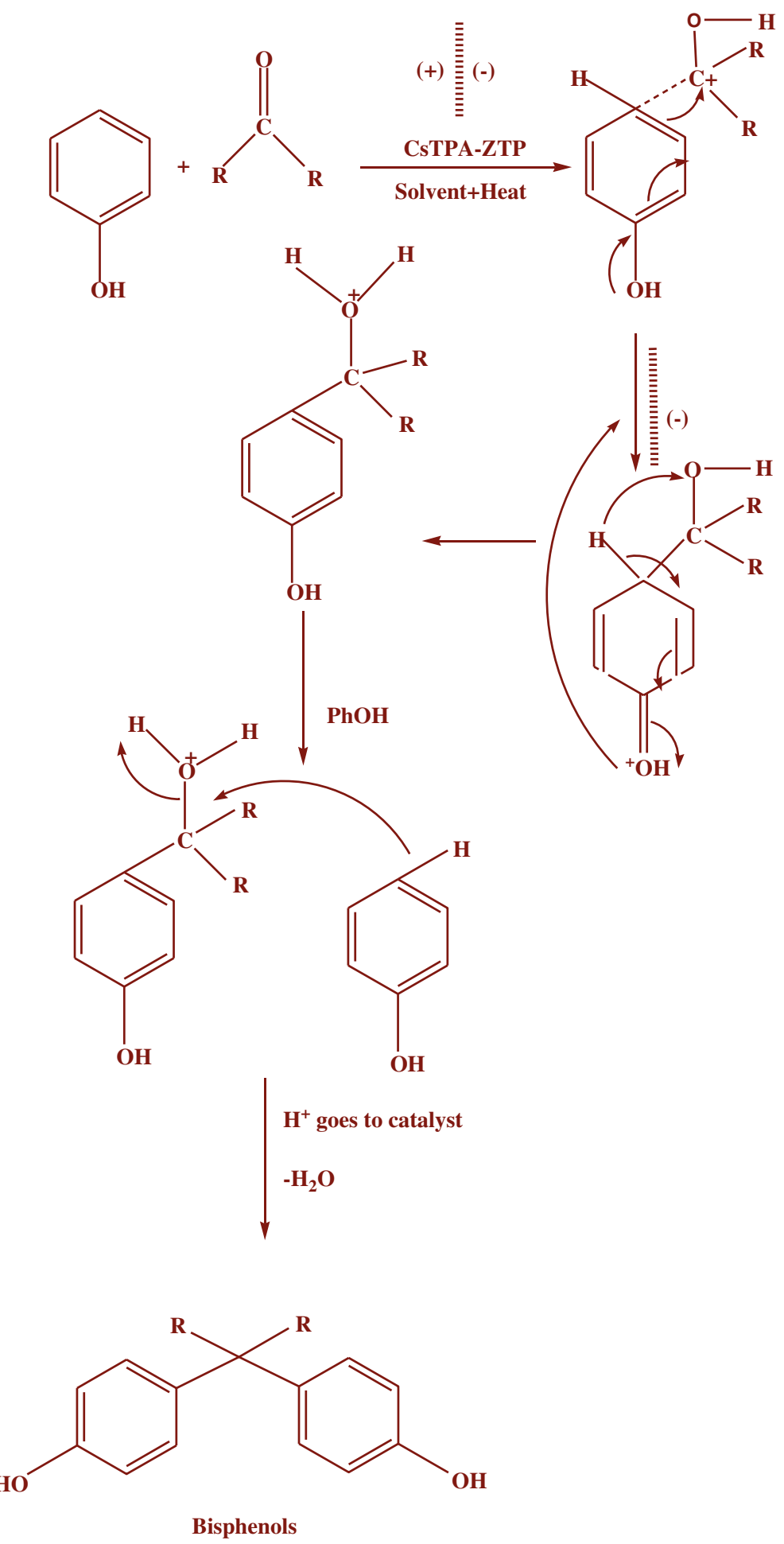

Scheme 2. Plausible mechanism for the formation of bisphenols over CsTPA-ZTP catalysts.

used catalysts. From figure 7(b), it is observed that there is no change in the important bands of the Keggin ion moety in used composite compared to unused one (figure 3b). This shows the stability of the catalyst towards the reaction conditions.

Scheme 2 shows that the condensation reaction occurs with two moles of phenolic compounds and one mole of aldehyde or ketone. The aldehyde or ketone undergoes chemisorption onto the catalyst surface. As seen in the TPD profiles (figure 5) and data analysis (table 2), the catalysts contain mainly Bronsted acid sites which help in forming electrophile. There is a first electrophilic attack on the phenol and formation of intermediate occurs. The second electrophilic attack 
Table 6. Comparison table for the formation of BPA/BPF over different catalysts.

\begin{tabular}{|c|c|c|c|c|c|}
\hline Entry & Catalyst & Temp $\left({ }^{\circ} \mathrm{C}\right)$ & Time (h) & Conversion $(\%)$ & References \\
\hline 1 & 60CsTPA@ZTP & 70 & 7 & $\begin{array}{l}61.73 \text { (BPA) } \\
71.20 \text { (BPF) }\end{array}$ & Present study \\
\hline 2 & MPS-8 & 70 & 24 & 29.6 & 8 \\
\hline 3 & $\begin{array}{c}15 \mathrm{Al}: \mathrm{MCM}-41 \\
\text { having a Si/Al ratio } \\
\text { of } 70 \mathrm{~mol} \mathrm{~mol}-1\end{array}$ & 90 & 4 & 93.1 & 23 \\
\hline 4 & $\mathrm{MCM}-\mathrm{SO}_{3} \mathrm{H}$ & 70 & 24 & 30 & 10 \\
\hline 5 & $\begin{array}{c}\text { Laccase from } \\
\text { Trametes versicolor } \\
(120 \mathrm{lM} \\
\text { BPA, } 0.15 \mathrm{U} / \mathrm{ml} \text { laccase })\end{array}$ & 25 & 1 & $\begin{array}{c}59.1 \\
- \\
\mathrm{pH} 5.0(25 \mathrm{mM} \\
\text { acetate buffer })\end{array}$ & 35 \\
\hline 6 & BPA with EC & 180 & $20 \mathrm{~min}$ & $\begin{array}{l}37 \\
-\end{array}$ & 36 \\
\hline 7 & Amberlyst XE-717p & 135 & 4 & 60 & 1 \\
\hline 8 & CsHPW/MCM-41 & 160 & 6 & 42 & 5 \\
\hline 9 & $\mathrm{Al}: \mathrm{MCM}-41$ & 90 & 1 & $63.2($ Yield $)$ & 37 \\
\hline 10 & $20 \% \mathrm{DTP} / \mathrm{SiO}_{2}$ & 80 & 1 & $34.2 \%$ (Yield) & 38 \\
\hline
\end{tabular}

takes place with a release of water molecule forming bisphenols. Catalysts having strong Bronsted acid sites can favour the formation of bisphenols. Hence, the supported catalysts are employed for this purpose.

Table 6 shows the BPA/BPF formation over other catalysts and comparison with the present study. It is observed that the present catalyst is comparable to that of the reported catalysts.

\section{Conclusion}

In summary, the present study emphasizes on a novel solid acid catalyst (60CsTPA-ZTP) which has been used in the liquid phase condensation reaction. Our recent results indicate that 60CsTPA-ZTP is an efficient catalyst for the condensation of $8 \mathrm{mmol}$ phenol and $1 \mathrm{mmol}$ acetone/formaldehyde at relatively low temperature $\left(70{ }^{\circ} \mathrm{C}\right)$ in $7 \mathrm{~h}$ to synthesize bisphenol $\mathrm{A} / \mathrm{bisphenol}$ F. It gives the highest conversion of $61.73 \%$ and $71.20 \%$ with selectivity of $85 \%$ and $88.35 \%$ towards bisphenol A/bisphenol F, respectively. Further, this study extends the possibility of using CsTPA-ZTP composite in other liquid phase acid-catalysed reactions.

\section{Acknowledgements}

Authors are thankful to Dr. K R Patil, National Chemical Laboratory (NCL), Pune for XPS analyses. One of the authors (NB) thanks the Council of Scientific and Industrial Research (CSIR) for Senior Research Fellowship.

\section{References}

1. Yadav G D and Kirthivasan N 1997 Appl. Catal. A: Gen. 15429

2. Jerabeck K, Hankova L, Prokop $\mathrm{Z}$ and Lundquist E G 2002 Appl. Catal. A: Gen. 232181

3. Kawase M, Inoue Y, Araki T and Hashimoto K 1999 Catal. Today 48199

4. Nowinska K and Kaleta W 2000 Appl. Catal. A: Gen. 20391

5. Singh A P 1992 Catal. Lett. 16431

6. Das D, Lee J-F and Cheng S 2004 J. Catal. 223152

7. Hou L, Cai Q, Lu B, Li X, Xiao X, Han Y and Cui S 2006 Catal. Lett. 111153

8. de Angelis A, Inallina P and Perego C 2004 Ind. Eng. Chem. Res. $\mathbf{4 3} 1169$

9. Okuhara T, Nishimura T, Watanabe $\mathrm{H}$ and Misono $\mathrm{M}$ 1992 J. Mol. Catal. 74247

10. Nishimura T, Okuhara T and Misono M 1991 Appl. Catal. 73 L7 
11. Na K, Okuhara T and Misono M 1995 J. Chem. Soc. Faraday Trans. 91367

12. Kimura M, Nakato T and Okuhara T 1997 Appl. Catal. A: Gen. 165227

13. Okuhara T, Kimura M and Nakato T 1997 Chem. Lett. 8839

14. Narasimharao K, Brown D R, Lee A F, Newman A D, Siril P F, Tavener S J and Wilson K 2007 J. Catal. 248 226

15. Okuhara T, Nishimura T and Misono M 1995 Chem. Lett. 155

16. Ide $\mathrm{Y}$, Kagawa N, Itakura M, Imae I, Sadakane M and Sano T 2012 ACS Appl. Mater. Interfaces 4 2186

17. Parida K M, Biswal N, Das D P and Martha S 2010 Int. J. Hydrogen Energ. 355262

18. Biswal N, Das D P, Martha S and Parida K M 2011 Int. J. Hydrogen Energ. 3613452

19. Biswal N, Martha S, Subudhi U and Parida K M 2011 Ind. Eng. Chem. Res. 509479

20. Biswal N and Parida K M 2013 Int. J. Hydrogen Energ. 381267

21. Zhang J, Sun M, Cao C, Zhang Q, Wang Y and Wan H 2010 Appl. Catal. A: Gen. 38087

22. Shimizu K, Kontani S, Yamada S, Takahashi G, Nihisyama T and Satsuma A $200818^{\text {th }}$ Saudi Arabia Joint Symposium, Dhahran, Saudi Arabia, November 16-17 1.

23. Jana S K, Kugita T and Namba S 2004 Appl. Catal. A: Gen. 266245
24. Yadav G D and George G 2009 Catal. Today 141130

25. Yadav G D and Asthana N S 2002 Ind. Eng. Chem. Res. 415565

26. Yadav G D, Asthana N S and Kamble V S 2003 Appl. Catal. A: Gen. 24053

27. Yadav G D and Asthana N S 2003 Appl. Catal. A: Gen. 244341

28. Yadav G D, Asthana N S and Kamble V S 2003 J. Catal. 217(1) 88

29. Choi S, Wang Y, Nie Z, Liu J and Peden C H F 2000 Catal. Today $\mathbf{5 5} 117$

30. Pesaresi L, Brown D R, Lee A F, Montero J M, Williams $\mathrm{H}$ and Wilson K 2009 Appl. Catal. A: Gen. 36050

31. Haber J, Matachowski L, Mucha D, Stoch J and Sarv P 2005 Inorg. Chem. 446695

32. Teterin Y A, Nefedov V I, Ronneau C, Vanbegin J, Cara J, Utkin I O, Teterin A Y, Nikitin A S, Ivanov K E, Vukcevic L and Bek-Uzarov G 2001 Radiochemistry 43604

33. Das D P, Biswal N, Martha S and Parida K M $2011 \mathrm{~J}$. Mol. Catal. A: Chem. 34936

34. Rode C V, Garade A C and Chikate R C 2009 Catal. Surv. Asia 13205

35. Kim Y-J and Nicell J A 2006 Bioresour. Technol. 97 1431

36. Oku A, Tanaka S and Hata S 2000 Polymer 416749

37. Jana S K, Kugita T and Namba S 2003 Catal. Lett. 90 143

38. Garade A C, Kshirsagar V S and Rode C V 2009 Appl. Catal. A: Gen. 354176 